\title{
High-Volume versus Low-Volume for Esophageal Resections for Cancer: The Essential Role of Case-Mix Adjustments based on Clinical Data
}

\author{
Michael W. Wouters, MD, ${ }^{1}$ Bas P. Wijnhoven, MD, PhD, ${ }^{3}$ Henrieke E. Karim-Kos, MSc, ${ }^{2}$ \\ Harriet G. Blaauwgeers, PhD, ${ }^{2}$ Laurents P. Stassen, MD, PhD, ${ }^{4}$ \\ Willem-Hans Steup, MD, PhD, ${ }^{5}$ Huug W. Tilanus, MD, PhD, ${ }^{3}$ and Rob A. Tollenaar, MD, $\mathrm{PhD}^{1}$
}

\author{
${ }^{1}$ Surgical Oncology, Leiden University Medical Center, Leiden, The Netherlands \\ ${ }^{2}$ Comprehensive Cancer Centre Leiden, Leiden, The Netherlands \\ ${ }^{3}$ Gastrointestinal Surgery, Erasmus University Medical Center, Rotterdam, The Netherlands \\ ${ }^{4}$ Department of Surgery, Reinier de Graaf Hospital, Delft, The Netherlands \\ ${ }^{5}$ Department of Surgery, HAGA Hospital, The Hague, The Netherlands
}

\begin{abstract}
Background: Most studies addressing the volume-outcome relationship in complex surgical procedures use hospital mortality as the sole outcome measure and are rarely based on detailed clinical data. The lack of reliable information about comorbidities and tumor stages makes the conclusions of these studies debatable.

The purpose of this study was to compare outcomes for esophageal resections for cancer in low- versus high-volume hospitals, using an extensive set of variables concerning case-mix and outcome measures, including long-term survival.

Methods: Clinical data, from 903 esophageal resections performed between January 1990 and December 1999, were retrieved from the original patients' files. Three hundred and fortytwo patients were operated on in 11 low-volume hospitals $(<7$ resections/year) and 561 in a single high-volume center.

Results: Mortality and morbidity rates were significantly lower in the high-volume center, which had an in-hospital mortality of 5 vs $13 \%(P<.001)$. On multivariate analysis, hospital volume, but also the presence of comorbidity proved to be strong prognostic factors predicting in-hospital mortality (ORs 3.05 and 2.34). For stage I and II disease, there was a significantly better 5 -year survival in the high-volume center. $(P=.04)$.

Conclusions: Hospital volume and comorbidity patterns are important determinants of outcome in esophageal cancer surgery. Strong clinical endpoints such as in-hospital mortality and survival can be used as performance indicators, only if they are joined by reliable case-mix information.
\end{abstract}

Key Words: Esophageal cancer-Esophagectomy-Surgical outcomes-High-volume hospitals - Case-mix - Comorbidity.

Since Luft published his study about the inverse relationship between surgical volume and hospital

Received March 21, 2007; accepted September 17, 2007; published online: November 15, 2007.

Address correspondence and reprint requests to: Michael W. Wouters, MD; E-mail: M.W.J.M.Wouters@lumc.nl

Published by Springer Science+Business Media, LLC $\odot$ The Author(s) 2007 mortality in 1979 , a plethora of studies has demonstrated an improvement of clinical outcome with increased hospital volume. ${ }^{1}$ Most of these studies use hospital mortality as the sole outcome measure. Often, data are obtained from insurance company's databases, and few studies use clinical data for riskadjustment. $^{2}$ 
The surgical treatment of esophageal cancer is often mentioned as one of the procedures for which concentration in high-volume centers might improve outcome. ${ }^{3,4}$ Nevertheless, a clear volume cut-off point at which a cancer center is justified to perform esophageal resections can hardly be defined. ${ }^{5,6}$ Also, the volume-outcome literature for esophageal resections is limited to postoperative mortality as the sole determinant of outcome.

Considering the growing evidence for this volumeoutcome relationship for esophageal cancer surgery, we decided to investigate the outcome of these procedures in our region from 1990 until 1999. During this study period none of the 11 hospitals affiliated with the Comprehensive Cancer Center Leiden (CCCL) in the Netherlands performed more than seven esophageal resections a year; all are considered low-volume hospitals (LVH).

In contrast to most volume-outcome studies, we decided to use clinical data obtained from the original patients' files. We retrieved information about comorbid diseases, tumor characteristics, treatment, and outcome. Next to hospital mortality, several determinants of outcome were examined, such as the number of tumor-free margins and complication rates. Assuming that survival is an essential indicator for quality in cancer surgery, we included a 5-year followup. To put our data in the right perspective, we compared these outcomes to the results of the topographically nearest high-volume referral center $(\mathrm{HVH})$.

\section{PATIENTS AND METHODS}

All surgically treated esophageal carcinomas in the period 1990-1999 were retrospectively identified through the Leiden Cancer Registry (LCR) of the Comprehensive Cancer Center Leiden (CCCL), in which all cancer patients treated in the midwestern part of the Netherlands are registered (1.7 million inhabitants). All 11 hospitals gave consent to participate in this audit and were visited by two investigators to retrieve the original patient files. Patient demographics, pathological notes, data on the surgical and (neo)adjuvant treatments, comorbidity as well as postoperative morbidity, mortality, length of stay, radicality of the resection, and long-term survival could all be retrieved from the patient's files.

All tumors were staged according to the UICC TNM classification of 1997. This was done by two independent researchers. The obtained pTNM stages were checked with the pTNM stages registered in the LCR. Any discrepancies were discussed between the researchers and a trained data manager from the CCCL. If consensus could not be reached, the pTNM stage was registered as "unknown."

To make a comparison with the outcomes of the nearest high-volume center, data were categorized according to the database of this center. In this hospital, data of patients operated on for an esophageal carcinoma are prospectively collected by a trained data manager.

Differences in patient, tumor, and treatment characteristics as well as outcome measurements were assessed using the Kruskal-Wallis test for continuous variables and the chi-square test for categorical variables. Logistic regression was used to determine prognostic factors of in-hospital mortality. Variables were entered in the multivariate model as a prognostic factor when $P$ values $<.10$.

Survival was calculated as the difference between date of surgery and either the date of death or the date of last patient follow-up. For both groups, follow-up of the patients was completed until December 31,2005 . Observed survival rates were estimated by using the Kaplan-Meier method. The log-rank test was used to assess differences in survival between patients who were operated in LVHs and the HVH. All analyses were conducted using SPSS software (version 12.0; SPSS Inc., Chicago. IL).

\section{RESULTS}

\section{Hospital Volume}

In 1990-1999 the evaluation and treatment of patients with an esophageal carcinoma were performed in 11 hospitals in the region of the CCCL (one university hospital, five teaching hospitals, and five general hospitals). In 342 patients the tumor was resected with curative intent. Figures $1 \mathbf{A}$ and $\mathbf{B}$ illustrate the distribution of surgical procedures within the studied time period and between the different hospitals. None of the CCCL hospitals performed more than seven esophageal resections a year, which makes them low-volume hospitals (LVHs). ${ }^{7}$ In the same period, 561 esophageal resections were performed in the nearest high-volume referral center $(\mathrm{HVH})$; a mean volume of 56 resections a year.

\section{Patient, Tumor, and Treatment Characteristics}

Table 1 shows the patient, tumor, and treatment characteristics of both groups. More patients from the $\mathrm{HVH}$ had a squamous cell carcinoma and an advanced stage of the disease. Operative strategy as well as 


\section{a}

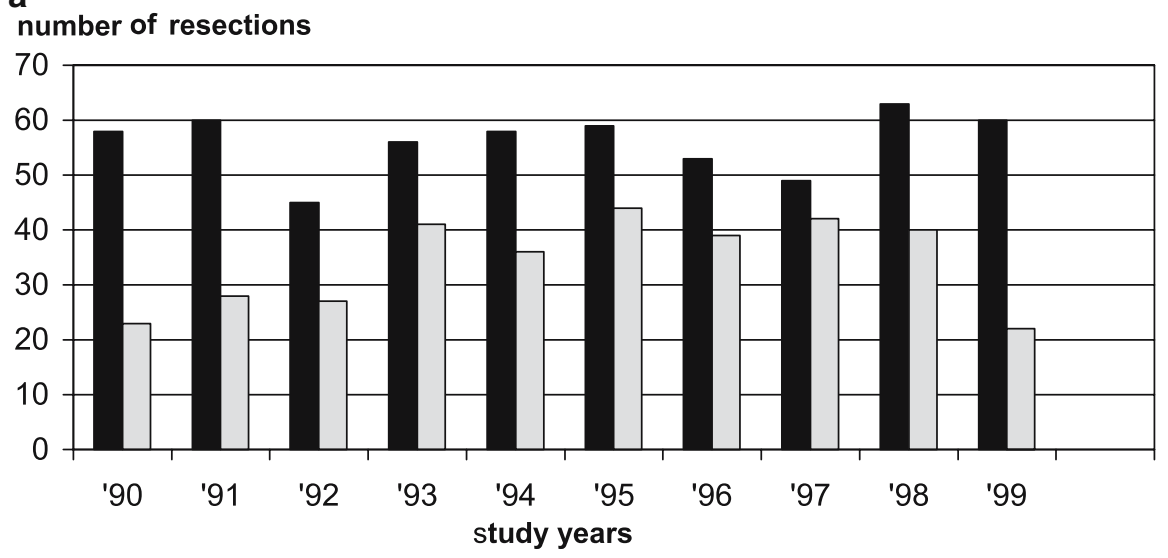

ש = high volume hospital (HVH)

= low volume hospitals (LVHs)

b

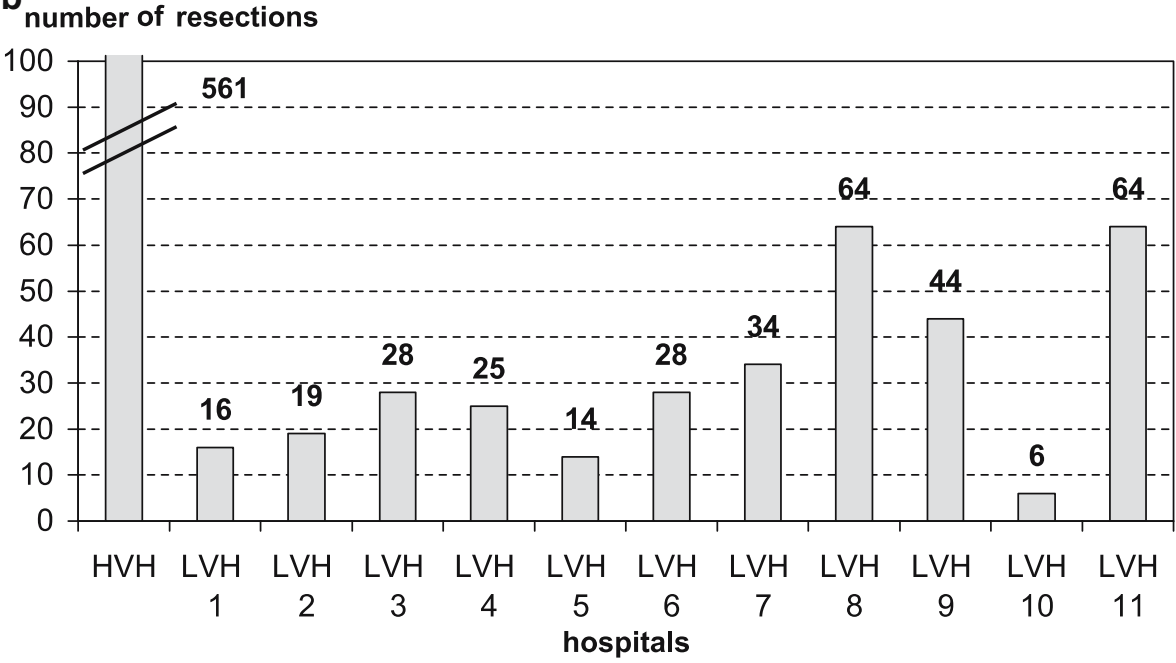

FIG. 1. (A) Number of esophageal resections per year in HVH versus LVH group (1990-1999). (B) Total number of esophageal resections per hospital for HVH and LVHs (1990-1999).

adjuvant or neoadjuvant treatment varied widely between the groups. The vast majority of resections in the $\mathrm{HVH}$ was performed according to the transhiatal technique, with a gastric tube reconstruction and anastomosis to the cervical remnant esophagus. In the LVH group a substantial number of anastomoses were located in the thoracic cavity, after a (partial) gastroesophagectomy with either a gastric tube reconstruction or esophagojejunostomy. In the pathology, clear surgical margins (R0) were reported in $72 \%$ and $67 \%$, respectively for the LVHs and the HVH group.

\section{Morbidity and Mortality}

A significantly higher postoperative morbidity rate was found in the LVH group, which probably is also reflected by the longer hospital stay (Table 2). The clinical anastomotic leakage rate differed between both groups: LVHs $17 \%$ versus HVH $5 \%$. The mortality rate was almost three times higher for patients treated in the LVHs than those who had their operation in the HVH: $13 \%$ vs $5 \%$, respectively $(P<$ $.001)$. None of the LVHs had a mortality rate lower than the 5\% of the HVH (Table 3). Univariate analysis showed that hospital volume, age, and comorbidity are prognostic factors for mortality (Table 4). The mortality risk increased with higher age and the number of organ systems affected. Especially cardiac (OR 3.22, CI 1.91-5.44), vascular (OR 2.49, CI 1.454.27), and respiratory (OR 1.90 CI 1.09-3.33) comorbidity were risk factors for postoperative mortality. 
TABLE 1. Patient, tumor, and treatment characteristics of esophageal resections in $\mathrm{LVH}^{a}$ and $H V H^{b}$

\begin{tabular}{|c|c|c|c|c|c|}
\hline \multirow[b]{2}{*}{ Characteristics } & \multicolumn{2}{|l|}{ LVH } & \multicolumn{2}{|l|}{$\mathrm{HVH}$} & \multirow[b]{2}{*}{$P$ value } \\
\hline & $\begin{array}{l}\text { No. of } \\
\text { patients }\end{array}$ & $\%$ & $\begin{array}{l}\text { No. of } \\
\text { patients }\end{array}$ & $\%$ & \\
\hline Age (years) & 65 & & 64 & & .240 \\
\hline Range (years) & $33-87$ & & $31-83$ & & \\
\hline Gender & & & & & .072 \\
\hline Male & 249 & 73 & 438 & 78 & \\
\hline Female & 93 & 27 & 123 & 22 & \\
\hline Comorbidity & & & & & .078 \\
\hline No & 142 & 42 & 273 & 49 & \\
\hline 1 organ system & 111 & 32 & 179 & 32 & \\
\hline 2 organ systems & 51 & 15 & 80 & 14 & \\
\hline$\geq 3$ organ systems & 11 & 3 & 27 & 5 & \\
\hline Unknown & 27 & 8 & 2 & 0 & \\
\hline Histology & & & & & .039 \\
\hline Adenocarcinoma & 238 & 69 & 347 & 62 & \\
\hline Squamous & 96 & 28 & 193 & 34 & \\
\hline Barrett's dysplasia & 4 & 1 & 6 & 1 & \\
\hline Other & 2 & 1 & 14 & 3 & \\
\hline Unknown & 2 & 1 & 1 & 0 & \\
\hline Tumor localization & & & & & .740 \\
\hline Cervical esophagus & 7 & 2 & 14 & 3 & \\
\hline Mid esophagus & 53 & 15 & 86 & 15 & \\
\hline Distal esophagus & 114 & 33 & 204 & 36 & \\
\hline Gastroesophageal junction & 166 & 49 & 251 & 45 & \\
\hline Unknown & 2 & 1 & 6 & 1 & \\
\hline Stage (pTNM) & & & & & $<.001$ \\
\hline 0 and $\mathrm{I}$ & 43 & 12 & 61 & 11 & \\
\hline II & 162 & 47 & 214 & 38 & \\
\hline III & 107 & 31 & 186 & 33 & \\
\hline IV & 21 & 6 & 94 & 17 & \\
\hline Unknown & 9 & 3 & 6 & 1 & \\
\hline (Neo)-adjuvant treatment & & & & & $<.001$ \\
\hline None & 316 & 92 & 464 & 83 & \\
\hline Chemotherapy & 17 & 5 & 93 & 17 & \\
\hline Radiotherapy & 0 & 0 & 2 & 0 & \\
\hline Chemoradiation & 4 & 1 & 0 & 0 & \\
\hline Unknown & 5 & 2 & 1 & 0 & \\
\hline Surgical approach & & & & & $<.001$ \\
\hline Abdomino-cervical & 150 & 44 & 466 & 83 & \\
\hline Thoraco-abdominal & 97 & 28 & 60 & 11 & \\
\hline Abdomino-thoraco-cervical & 43 & 13 & 17 & 3 & \\
\hline Abdominal & 52 & 15 & 18 & 3 & \\
\hline Anastomoses & & & & & $<.001$ \\
\hline Cervical & 195 & 57 & 541 & 96 & \\
\hline Thoracic & 91 & 27 & 8 & 2 & \\
\hline Abdominal & 56 & 16 & 8 & 2 & \\
\hline Unknown & 0 & 0 & 4 & 0 & \\
\hline Total No. of patients & 342 & & 561 & & \\
\hline
\end{tabular}

${ }^{a}$ LVH, low-volume hospitals.

${ }^{b} \mathrm{HVH}$, high-volume hospital.

Multivariate analysis showed that both hospital volume and comorbidity were independent prognostic factors for hospital mortality (Table 5).

\section{Survival}

Figure 2 shows the crude 10-year overall survival rate of all patients, in which an esophageal resection for cancer was performed. Survival rates for patients
TABLE 2. Outcome after resection of esophagus for cancer in $\mathrm{LVH}^{a}$ and $\mathrm{HVH} \mathrm{H}^{b}$

\begin{tabular}{|c|c|c|c|c|c|}
\hline \multirow[b]{2}{*}{ Outcome } & \multicolumn{2}{|l|}{ LVH } & \multicolumn{2}{|l|}{$\mathrm{HVH}$} & \multirow[b]{2}{*}{$P$ value } \\
\hline & $\begin{array}{l}\text { No. of } \\
\text { patients }\end{array}$ & $\%$ & $\begin{array}{l}\text { No. of } \\
\text { patients }\end{array}$ & $\%$ & \\
\hline Margins & & & & & .93 \\
\hline R0 & 248 & 72 & 377 & 67 & \\
\hline R1 & 55 & 16 & 161 & 28 & \\
\hline $\mathrm{R} 2$ & 35 & 11 & 21 & 4 & \\
\hline Unknown & 4 & 1 & 2 & 1 & \\
\hline \multicolumn{6}{|l|}{ Complications } \\
\hline Surgical complications & 144 & 42 & 207 & 37 & .01 \\
\hline General complications & 191 & 56 & 207 & 37 & $<.001$ \\
\hline No complications & 89 & 26 & 247 & 44 & $<.001$ \\
\hline \multicolumn{6}{|l|}{ Hospital stay } \\
\hline Median (days) & 21 & & 14 & & $<.001$ \\
\hline \multicolumn{6}{|l|}{ In-hospital } \\
\hline Mortality & 45 & 13 & 28 & 5 & $<.001$ \\
\hline Survival & & & & & \\
\hline Median (months) & 21 & & 22 & & .90 \\
\hline Range (months) & $(1-171)$ & & $(1-158)$ & & \\
\hline Total No. of patients & 342 & & 561 & & \\
\hline
\end{tabular}

TABLE 3. Mortality after resection of esophagus for cancer in $\mathrm{LVH}^{a}$ and $\mathrm{HVH}^{b}$

\begin{tabular}{lclr}
\hline & \multicolumn{3}{c}{ In-hospital mortality } \\
\cline { 2 - 4 } Hospitalsm & No. of patients & No. of deaths & $\%$ \\
\hline HVH & 561 & 28 & 5.0 \\
LVH 1 & 16 & 2 & 12.5 \\
LVH 2 & 19 & 2 & 10.5 \\
LVH 3 & 28 & 2 & 7.1 \\
LVH 4 & 25 & 3 & 12.0 \\
LVH 5 & 14 & 1 & 7.1 \\
LVH 6 & 28 & 2 & 7.1 \\
LVH 7 & 34 & 2 & 5.9 \\
LVH 8 & 64 & 12 & 18.7 \\
LVH 9 & 44 & 10 & 22.7 \\
LVH 10 & 6 & 2 & 33.3 \\
LVH 11 & 64 & 7 & 10.9 \\
Total No. of patients & 903 & 73 & 8 \\
\hline
\end{tabular}

${ }^{a}$ LVH, low-volume hospitals.

${ }^{b}$ HVH, high-volume hospital.

treated in the HVH are significantly better $(P=.01)$. This survival benefit loses its statistical significance, after exclusion of patients who died postoperatively of complications of the surgical procedure (Fig. 3). Only, when we select patients with stage I and II disease do we see a better survival in the $\mathrm{HVH}$ (Fig. 4), meaning that its overall results are worsened by the poor survival in the higher stages of the disease, stage III and IV. This can be explained by the unfavorable tumor mix, with significantly more stage IV disease treated in the $\mathrm{HVH}$, than in the LVHs (16.7 vs $6.1 \%$ ). 
TABLE 4. Univariate analysis of in-hospital mortality

\begin{tabular}{|c|c|c|c|}
\hline & \multicolumn{3}{|c|}{ Univariate analysis } \\
\hline & OR & $95 \% \mathrm{CI}$ & $P$ value \\
\hline Region & & & $<.001$ \\
\hline HVH & 1.00 & $\operatorname{Ref}^{a}$ & \\
\hline LVH & 2.88 & $1.76-4.72$ & \\
\hline Age (years) & & & .01 \\
\hline$<50$ & 0.19 & $0.04-0.79$ & \\
\hline $50-59$ & 0.51 & $0.25-1.04$ & \\
\hline $60-69$ & 1.00 & $\operatorname{Ref}^{a}$ & \\
\hline$>70$ & 1.20 & $0.70-2.04$ & \\
\hline Gender & & & .20 \\
\hline Male & 1.00 & $\operatorname{Ref}^{a}$ & \\
\hline Female & 0.67 & $0.36-1.24$ & \\
\hline Comorbidity & & & $<.001$ \\
\hline No & 1.00 & $\operatorname{Ref}^{a}$ & \\
\hline 1 organ system & 2.02 & $1.06-3.86$ & \\
\hline 2 organ systems & 4.51 & $2.30-8.85$ & \\
\hline$\geq 3$ organ systems & 4.97 & $1.92-12.83$ & \\
\hline Histology & & & .97 \\
\hline Adenocarcinoma & 1.00 & $\operatorname{Ref}^{a}$ & \\
\hline Squamous & 0.99 & $0.60-1.65$ & \\
\hline Stage & & & .24 \\
\hline I & 1.00 & $\operatorname{Ref}^{a}$ & \\
\hline II & 0.50 & $0.24-1.04$ & \\
\hline III & 0.80 & $0.39-1.63$ & \\
\hline IV & 0.65 & $0.26-1.61$ & \\
\hline Tumor localization & & & .33 \\
\hline Cervical/mid esophagus & 1.00 & $\operatorname{Ref}^{a}$ & \\
\hline $\begin{array}{l}\text { Distal esophagus/ } \\
\text { gastroesophageal junction }\end{array}$ & 1.41 & $0.71-2.80$ & \\
\hline Neoadjuvant treatment & & & .14 \\
\hline No & 1.00 & $\operatorname{Ref}^{a}$ & \\
\hline Yes & 0.49 & $0.20-1.25$ & \\
\hline Surgical approach & & & .31 \\
\hline Transhiatal & 1.00 & $\operatorname{Ref}^{a}$ & \\
\hline Transthoracic & 1.51 & $0.90-2.54$ & .12 \\
\hline Anastomosis & & & .46 \\
\hline Cervical & 1.00 & $\operatorname{Ref}^{a}$ & \\
\hline Thoracic & 1.52 & $0.77-3.01$ & \\
\hline Abdominal & 1.26 & $0.52-3.04$ & \\
\hline
\end{tabular}

${ }^{a}$ Ref, reference category.

\section{DISCUSSION}

Currently, there is extensive interest in comparing outcome of complex surgical procedures between high- and low-volume providers. Most of the studies are registry-based or relatively small. Our series offers additional proof to the volume-outcome relationship, because it is based on clinical data, retrieved from the original patient files. This allows us to make reliable comparisons for comorbidities and tumor stage, which proved to be important prognostic factors for in-hospital mortality and survival.

A review of the evidence for a volume-outcome relationship was published by Dudley in $2000^{8}$ and Halm in 2002. ${ }^{2}$ In the latter publication 135 studies were reviewed, of which only five were not from the United States or Canada. The majority of reports
TABLE 5. Multivariate analysis of in-hospital mortality

\begin{tabular}{lllr}
\hline & \multicolumn{3}{l}{ Multivariate analysis } \\
\cline { 2 - 4 } & OR & $95 \%$ CI & $P$ value \\
\hline Region & & & $<.001$ \\
HVH & 1.00 & $\operatorname{Ref}^{a}$ & \\
LVHs & 3.05 & $1.82-5.11$ & .10 \\
Age (years) & & & \\
$<50$ & 0.22 & $0.05-0.96$ & \\
$50-59$ & 0.60 & $0.29-1.25$ & .004 \\
$60-69$ & 1.00 & $\operatorname{Ref}^{a}$ & \\
$>70$ & 1.07 & $0.61-1.88$ & \\
Comorbidity & & & \\
No & 1.00 & $\operatorname{Ref}^{a}$ & \\
Yes & 2.34 & $1.30-4.19$ & \\
\hline
\end{tabular}

${ }^{a}$ Ref, Reference category.

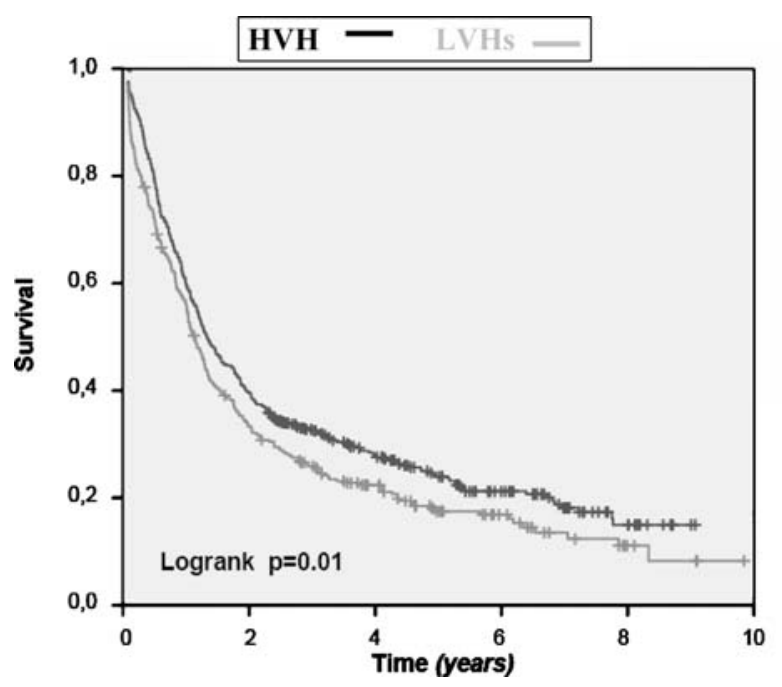

FIG. 2. Overall survival after esophagus resection for cancer: LVHs vs HVH (in-hospital mortality included).

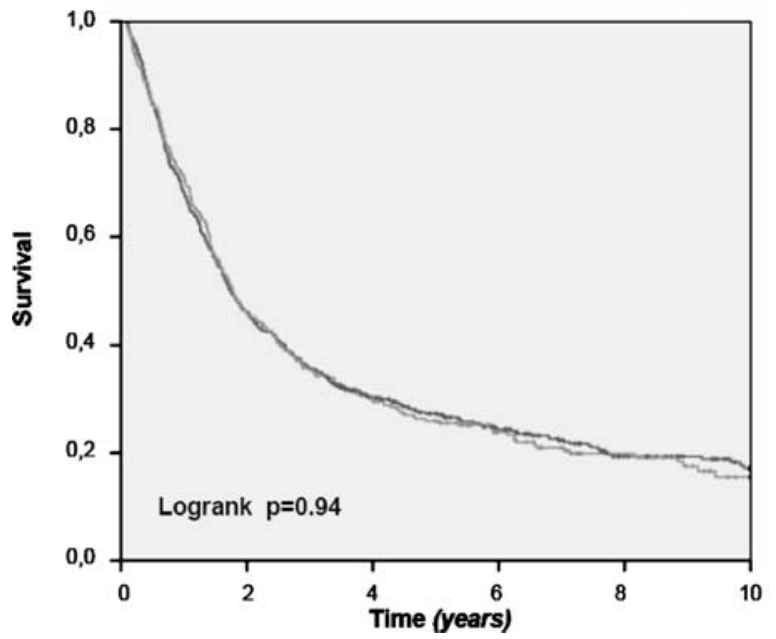

FIG. 3. Overall survival after esophagus resection for cancer: LVHs vs HVH (in-hospital mortality excluded). 


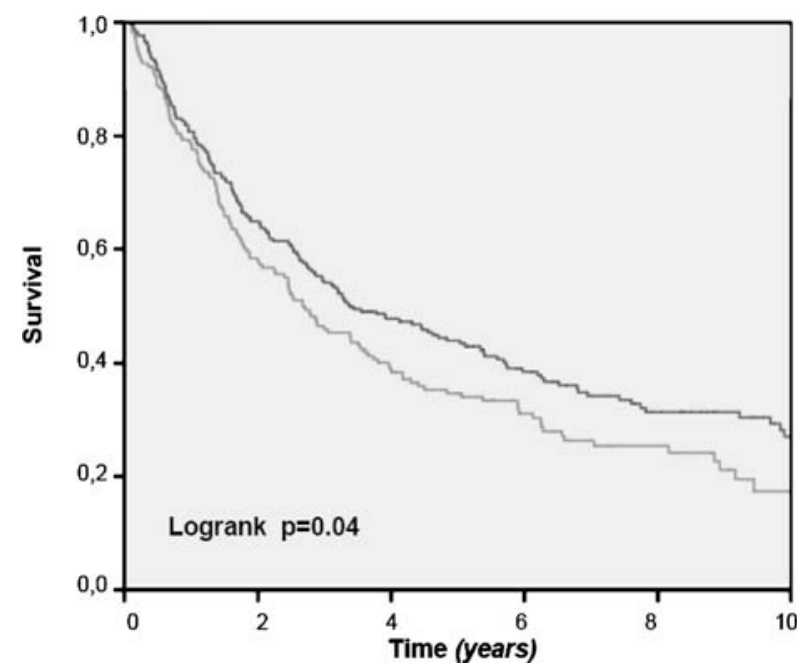

FIG. 4. Overall survival after esophagus resection for stage I and II carcinoma: LVHs vs HVH (in-hospital mortality excluded).

were based on state or national hospital discharge databases, where only a few studies used clinical data for risk adjustment. The outcome measure was "death" in $79 \%$ of the studies, without analyzing other dimensions of "outcome," such as morbidity, length of hospital stay, reoperations, et cetera. For cancer-related procedures, long-term survival was not mentioned. Higher-level methodological issues were rarely addressed. Only five studies concerning cancer treatment adjusted for (neo)-adjuvant therapies or the type of surgical resection, but without any adjustment for tumor stage.

Since 2002, more extensive studies on hospital or surgeon volume appeared in the international literature. Birkmeyer reported a total number of 2.5 million operations concerning 14 different surgical procedures derived from the MEDICARE database. ${ }^{9}$ Mortality was the only outcome measure. Even after risk adjustment, which decreased the outcome differences between high- and low-volume hospitals, the differences in results for esophageal and pancreatic resections were highly significant, favoring surgery in a high-volume center. Two more recently published reviews of the volume-outcome relationship for esophagectomies came up with 12 papers addressing this subject. ${ }^{4,5}$ Only two of these studies were based on clinical data. Although both showed a decrease in mortality, they failed to show a statistically significant relationship of operative mortality with hospital volume. $^{10,11}$ In our own review of the literature we identified another study from the United Kingdom using clinical data, in which hospital case volume independently predicted operative mortality ${ }^{2}$ (Table 6).
In the present study, independent data managers collected data retrospectively from the patient files. Not only the (in-hospital) mortality rate was obtained, but also a range of other outcome data, such as complication rates, resection margins, length of stay, and long-term survival. In our opinion the latter is an important performance indicator in surgical oncology, surprisingly sporadically mentioned in the volume-outcome literature.

The results of patients treated in 11 low-volume hospitals were compared with the results of patients treated in the nearest high-volume referral center. Significant differences in outcome could be revealed. In-hospital mortality was significantly higher in the low-volume hospitals. The retrieved information about comorbidity and stage of the disease made an extensive preoperative risk and tumor load comparison possible. Risk adjustment is an important issue in outcome research, because patients with severe comorbidity may be unequally distributed between (groups of) hospitals. Especially, when only administrative data are used to assess hospital performances, a selection-bias could lead to inadvertently penalizing those surgeons who provide excellent care to patients with more severe comorbid disease. ${ }^{7,13}$ Administrative data sets were never designed to predict risk and should probably not be used as such. ${ }^{14}$ Therefore, the validity of studies that fail to make case-mix adjustments based on clinical data, has to be questioned.

Nevertheless, a multivariate analysis of our data shows hospital volume to be an independent prognostic factor for in-hospital mortality. Although differences in surgical technique could be detected, with more transthoracic esophagectomies and intrathoracic anastomoses in the low-volume group, these factors are not significantly related to mortality. These findings are confirmed by earlier reports. ${ }^{15-18}$ Also, there is little evidence for a beneficial role of neoadjuvant therapies. ${ }^{19-22}$ However, above all, choices made concerning diagnostic strategy, neoadjuvant treatments, and surgical technique are related to the knowledge, experience, and judgment of the (team of) specialists.

After exclusion of in-hospital mortality, the survival of patients in the HVH was equal to those treated in the LVHs. However, the results of the HVH were negatively influenced by its case-mix. More patients with stage IV disease were treated in the $\mathrm{HVH}$, corresponding with its status as a tertiary referral center. The very poor survival in this group of patients influences the overall results significantly. Only when we are informed about differences in tu- 
TABLE 6. Volume-outcome articles for in-hospital mortality after esophagectomy 1998-2006

\begin{tabular}{|c|c|c|c|c|}
\hline Author & Journal/Year & Data & Volume "cut-off", & Conclusion \\
\hline Dimick et al. ${ }^{32}$ & Ann Thorac Surg 2005 & Adm & $<6>$ & $\mathrm{S}$ \\
\hline Urbach and Baxter ${ }^{33}$ & BMJ 2004 & Adm & $<9>$ & NS \\
\hline McCulloch et al. ${ }^{12}$ & BMJ 2003 & Clin & $<10-20>$ & $\mathrm{S}$ \\
\hline Christian et al.34 & Ann Surg 2003 & Adm & $<22>$ & $\mathrm{S}$ \\
\hline Finlayson et al. ${ }^{35}$ & Arch Surg 2003 & Adm & $<4-9>$ & $\mathrm{S}$ \\
\hline Urbach et al. $^{36}$ & CMAJ 2003 & Adm & a & $\mathrm{S}$ \\
\hline Dimick et al. ${ }^{37}$ & Surgery 2003 & Adm & $<7>$ & $\mathrm{S}$ \\
\hline Birkmeyer et al. $^{9}$ & $N$ Engl J Med 2002 & Adm & $<2-4-7-19>$ & $\mathrm{S}$ \\
\hline Gillison et al. ${ }^{11}$ & BrJ Surg 2002 & Clin & $<19>$ & NS \\
\hline Bachmann et al. ${ }^{10}$ & Br J Surg 2002 & Clin & $a$ & NS \\
\hline Dimick et al. ${ }^{38}$ & Ann Thorac Surg 2001 & Adm & $<4-15>$ & $\mathrm{S}$ \\
\hline van Lanschot et al. ${ }^{7}$ & Cancer 2001 & Adm & $<10-20>$ & $\mathrm{S}$ \\
\hline Kuo et al. ${ }^{39}$ & Ann Thorac Surg 2001 & Adm & $<6>$ & $\mathrm{S}$ \\
\hline Swisher et al. ${ }^{40}$ & $J$ Thorac Cardiovasc Surg 2000 & Adm & $<5>$ & $\mathrm{S}$ \\
\hline Gordon et al. ${ }^{41}$ & J Am Coll Surg 1999 & Adm & $<10-20-50>$ & $\mathrm{S}$ \\
\hline Begg et al. ${ }^{42}$ & JAMA 1998 & Mixed & $<5-10>$ & $\mathrm{S}$ \\
\hline Patti et al. ${ }^{43}$ & J Gastrointest Surg 1998 & Adm & $<1-2-4-6>$ & $\mathrm{S}$ \\
\hline
\end{tabular}

${ }^{a}$ Urbach and Bachmann used equally sized groups and reported only median volumes of these groups.

Adm denotes administrative data; Clin denotes clinical data; S denotes significant; NS denotes not significant.

mor stage, we are able to detect real differences in survival between patients treated in different hospitals. Although in this study, all pathology reports were reviewed, and the number of lymph nodes resected was equal for both groups, we still have to be cautious suggesting a survival benefit for high-volume surgery. Only when a uniform pathologic evaluation is guaranteed, can we be sure that observed differences in tumor stages are truly characteristic for patient groups. This could be the reason that few studies have attempted to examine the influence of hospital volume on long-term survival in cancer surgery, only one of them concerning esophagectomies. ${ }^{23-27} \mathrm{~A}$ recent study from the Netherlands failed to show a survival benefit in high-volume hospitals $(>20$ resections a year), but did show an improved survival for esophagectomies performed in university compared to non-university hospitals. ${ }^{28}$ On the other hand, for pancreatectomies and hepatectomies registered in the MEDICARE-database, Fong showed a significantly better survival for procedures performed in high-volume centers. ${ }^{25}$ In his study, administrative data about age, gender, comorbidity, and extent of the resection were included in a univariate and multivariate analysis, but stages of the disease, radicality, and intent of the resection (palliative or curative) were not reported.

In conclusion, our study shows that hospital volume is an important determinant of perioperative morbidity and mortality in esophageal cancer surgery. Nevertheless, volume in itself is no guarantee for high quality of surgical care in a specific institution. Selecting (only) favorable patients can be the basis of superior results. Therefore, case-mix adjust- ments are essential in the assessment of surgical performance of different institutions.

\section{OPEN ACCESS}

This article is distributed under the terms of the Creative Commons Attribution Noncommercial License which permits any noncommercial use, distribution, and reproduction in any medium, provided the original author(s) and source are credited.

\section{REFERENCES}

1. Luft HS, Bunker JP, Enthoven AC. Should operations be regionalized? The empirical relation between surgical volume and mortality. N Engl J Med 1979; 301:1364-9.

2. Halm EA, Lee C, Chassin MR. Is volume related to outcome in health care? A systematic review and methodologic critique of the literature. Ann Intern Med 2002; 137:511-20.

3. Birkmeyer JD, Siewers AE, Finlayson EV, et al. Hospital volume and surgical mortality in the United States. $N$ Engl $J$ Med 2002; 346:1128-37.

4. Killeen SD, O’Sullivan MJ, Coffey JC, Kirwan WO, Redmond HP. Provider volume and outcomes for oncological procedures. Br J Surg 2005; 92:389-402.

5. Metzger R, Bollschweiler E, Vallbohmer D, Maish M, DeMeester TR, Holscher AH. High volume centers for esophagectomy: what is the number needed to achieve low postoperative mortality? Dis Esophagus 2004; 17:310-4.

6. Holscher AH, Metzger R, Brabender J, Vallbohmer D, Bollschweiler E. High-volume centers - effect of case load on outcome in cancer surgery. Onkologie 2004; 27:412-6.

7. van Lanschot JJ, Hulscher JB, Buskens CJ, Tilanus HW, ten Kate FJ, Obertop H. Hospital volume and hospital mortality for esophagectomy. Cancer 2001; 91:1574-8.

8. Dudley RA, Johansen KL, Brand R, Rennie DJ, Milstein A. Selective referral to high-volume hospitals: estimating potentially avoidable deaths. JAMA 2000; 283:1159-66. 
9. Birkmeyer JD, Siewers AE, Finlayson EV, et al. Hospital volume and surgical mortality in the United States. $N$ Engl $J$ Med 2002; 346:1128-37.

10. Bachmann MO, Alderson D, Edwards D, Wotton S, Bedford C, Peters TJ, Harvey IM. Cohort study in South and West England of the influence of specialization on the management and outcome of patients with oesophageal and gastric cancers. Br J Surg 2002; 89:914-22.

11. Gillison EW, Powell J, McConkey CC, Spychal RT. Surgical workload and outcome after resection for carcinoma of the oesophagus and cardia. Br J Surg 2002; 89:344-8.

12. McCulloch P, Ward J, Tekkis PP. Mortality and morbidity in gastro-oesophageal cancer surgery: initial results of ASCOT multicentre prospective cohort study. BMJ 2003; 327:1192-7.

13. Urbach DR, Bell CM. The effect of patient selection on comorbidity-adjusted operative mortality risk. Implications for outcomes studies of surgical procedures. J Clin Epidemiol 2002; 55:381-5.

14. Iezzoni LI. Assessing quality using administrative data. Ann Intern Med 1997; 127:666-74.

15. Chasseray VM, Kiroff GK, Buard JL, Launois B. Cervical or thoracic anastomosis for esophagectomy for carcinoma. Surg Gynecol Obstet 1989; 169:55-62.

16. Goldminc M, Maddern G, Le Prise E, Meunier B, Campion JP, Launois B. Oesophagectomy by a transhiatal approach or thoracotomy: a prospective randomized trial. Br J Surg 1993 80:367-70.

17. Hulscher JB, van Sandick JW, de Boer AG, et al. Extended transthoracic resection compared with limited transhiatal resection for adenocarcinoma of the esophagus. $N$ Engl J Med 2002; 347:1662-9.

18. Ribet M, Debrueres B, Lecomte-Houcke M. Resection for advanced cancer of the thoracic esophagus: cervical or thoracic anastomosis? Late results of a prospective randomized study. $J$ Thorac Cardiovasc Surg 1992; 103:784-9.

19. Arnott SJ, Duncan W, Kerr GR, et al. Low dose preoperative radiotherapy for carcinoma of the oesophagus: results of a randomized clinical trial. Radiother Oncol 1992; 24:108-13.

20. Malthaner RA, Wong RK, Rumble RB, Zuraw L. Neoadjuvant or adjuvant therapy for resectable esophageal cancer: a systematic review and meta-analysis. BMC Med 2004; 2:35.

21. Urba SG, Orringer MB, Turrisi A, Iannettoni M, Forastiere A Strawderman M. Randomized trial of preoperative chemoradiation versus surgery alone in patients with locoregional esophageal carcinoma. J Clin Oncol 2001; 19:305-3.

22. Walsh TN, Noonan N, Hollywood D, Kelly A, Keeling N, Hennessy TP. A comparison of multimodal therapy and surgery for esophageal adenocarcinoma. $N$ Engl J Med 1996; 335:462-7.

23. Bach PB, Cramer LD, Schrag D, Downey RJ, Gelfand SE, Begg CB. The influence of hospital volume on survival after resection for lung cancer. $N$ Engl J Med 2001; 345:181-8.

24. Birkmeyer JD, Warshaw AL, Finlayson SR, Grove MR, Tosteson AN. Relationship between hospital volume and late survival after pancreaticoduodenectomy. Surgery 1999; 126:178-83

25. Fong $\mathrm{Y}$, Gonen M, Rubin D, Radzyner M, Brennan MF. Long-term survival is superior after resection for cancer in high-volume centers. Ann Surg 2005; 242:540-4.

26. Roohan PJ, Bickell NA, Baptiste MS, Therriault GD, Ferrara EP, Siu AL. Hospital volume differences and five-year survival from breast cancer. Am J Public Health 1998; 88:454-7.
27. Schrag D, Cramer LD, Bach PB, Cohen AM, Warren JL, Begg CB. Influence of hospital procedure volume on outcomes following surgery for colon cancer. JAMA 2000; 284:3028-35.

28. Verhoef C, van de WR, Schaapveld M, Bastiaannet E, Plukker JT. Better Survival in Patients with Esophageal Cancer After Surgical Treatment in University Hospitals: A Plea for Performance by Surgical Oncologists. Ann Surg Oncol 2007;14:1678-87.

29. Birkmeyer JD, Dimick JB, Birkmeyer NJ. Measuring the quality of surgical care: structure, process, or outcomes?. $J \mathrm{Am}$ Coll Surg 2004; 198:626-32.

30. van Heek NT, Kuhlmann KF, Scholten RJ, et al. Hospital volume and mortality after pancreatic resection: a systematic review and an evaluation of intervention in the Netherlands. Ann Surg 2005; 242:781-8; discussion.

31. O'Connor GT, Plume SK, Olmstead EM, et al. A regional intervention to improve the hospital mortality associated with coronary artery bypass graft surgery. The Northern New England Cardiovascular Disease Study Group. JAMA 1996; 275:841-6.

32. Dimick JB, Wainess RM, Upchurch GR Jr., Iannettoni MD, Orringer MB. National trends in outcomes for esophageal resection. Ann Thorac Surg 2005; 79:212-6.

33. Urbach DR, Baxter NN. Does it matter what a hospital is "high volume" for? Specificity of hospital volume-outcome associations for surgical procedures: analysis of administrative data. $B M J$ 2004; 328:737-40.

34. Christian CK, Gustafson ML, Betensky RA, Daley J, Zinner MJ. The Leapfrog volume criteria may fall short in identifying high-quality surgical centers. Ann Surg 2003; 238:447-55.

35. Finlayson EV, Goodney PP, Birkmeyer JD. Hospital volume and operative mortality in cancer surgery: a national study. Arch Surg 2003; 138:721-5.

36. Urbach DR, Bell CM, Austin PC. Differences in operative mortality between high- and low-volume hospitals in Ontario for 5 major surgical procedures: estimating the number of lives potentially saved through regionalization. CMAJ 2003; 168:1409-14.

37. Dimick JB, Pronovost PJ, Cowan JA Jr., Lipsett PA, Stanley JC, Upchurch GR Jr. Variation in postoperative complication rates after high-risk surgery in the United States. Surgery 2003; 134:534-40.

38. Dimick JB, Cattaneo SM, Lipsett PA, Pronovost PJ, Heitmiller RF. Hospital volume is related to clinical and economic outcomes of esophageal resection in Maryland. Ann Thorac Surg 2001; 72:334-9.

39. Kuo EY, Chang Y, Wright CD. Impact of hospital volume on clinical and economic outcomes for esophagectomy. Ann Thorac Surg 2001; 72:1118-24.

40. Swisher SG, Deford L, Merriman KW, et al. Effect of operative volume on morbidity, mortality, and hospital use after esophagectomy for cancer. J Thorac Cardiovasc Surg 2000; 119:1126-32.

41. Gordon TA, Bowman HM, Bass EB, et al. Complex gastrointestinal surgery: impact of provider experience on clinical and economic outcomes. J Am Coll Surg 1999; 189:46-56.

42. Begg CB, Cramer LD, Hoskins WJ, Brennan MF. Impact of hospital volume on operative mortality for major cancer surgery. JAMA 1998; 280:1747-51.

43. Patti MG, Corvera CU, Glasgow RE, Way LW. A hospital's annual rate of esophagectomy influences the operative mortality rate. J Gastrointest Surg 1998; 2:186-92. 